\title{
LOS MEDALLONES PEQUEÑOS DEL CORO ALTO DE LA SILLERÍA DE LA CATEDRAL DE CÓRDOBA ${ }^{1}$
}

\author{
POR \\ BENITO NAVARRETE PRIETO \\ Universidad de Alcalá
}

Study about the engraving and drawing sources that Pedro Duque Cornejo used for the little medallions of the upper choir in the Choir-Stalls of the Cordoba Cathedral made between 1747-1757.

Presentamos un estudio sobre las fuentes grabadas que utilizó Pedro Duque Cornejo para los medallones pequeños del coro alto de la Sillería de la Catedral de Córdoba, obra ejecutada entre 1747 y 1757. Primeramente analizamos los diferentes juicios críticos que la sillería ha recibido, pasando luego al estudio de los relieves en relación con las estampas de la Biblia ilustrada publicada en Venecia por Pezzana, que posiblemente le fuera suministrada por los propios comitentes de la obra. Con respecto a estos relieves, Moreno Cuadro había evidenciado el uso de estampas en cinco de ellos. En nuestro trabajo damos a conocer relaciones evidentes en otros trece medallones. Apoyamos nuestros argumentos en los indudables paralelos formales y en la documentación contenida en el libro de cuentas de la Sillería.

El juicio crítico que la sillería de coro de la Catedral de Córdoba ha merecido a lo largo de los tiempos ha sido variado y desigual y, sobre todo, fiel exponente de lo que a lo largo de la historia supone el mudar del gusto ${ }^{2}$.

En 1778, sólo ventiún años después de su construcción, Juan Gómez Bravo en su catálogo de Obispos de Córdoba ${ }^{3}$, nos habla de que la sillería «es obra la mayor de su clase en España por sus bellas medallas, estatuas y delicada escultura». Posteriormente, D. Antonio Ponz en su

\footnotetext{
${ }^{1}$ Con mi agradecimiento a la Dra. María Luisa Tárraga Baldó e Isabel Mateo y a D. Manuel Nieto Cumplido, por sus facilidades en la realización de las fotografías de la Sillería de la Catedral de Córdoba.

2 S.C. «La Sillería del Coro de la Catedral de Córdoba y sus críticos» en Boletín de la Sociedad Española de Excursiones, T. XXVII, 1919, pp. 124-126. En este artículo se presentan los principales juicios críticos sobre la Sillería cordobesa.

Para un análisis crítico de la bibliografía referente a la sillería de coro cordobesa, véase nuestro trabajo; «Las sillerías de coro barrocas en la historiografía artística española» en VII Jornadas de Arte; La Historiografía del arte español en los siglos XIX y XX, Dpto. de $\mathrm{H}^{\mathrm{a}}$ del Arte, C.S.I.C., Madrid, 1995, pp.209-221.

${ }^{3}$ Gómez Bravo, J. Catálogo de los Obispos de Córdoba y breve noticia histórica de su iglesia Catedral y obispado, Córdoba, 1778, T.II, p. 816.
} 
Viaje de España ${ }^{4}$ nos dice que la Sillería cordobesa es «... un trabajo inmenso, obra de nuestro siglo, que necesariamente hubo de ser muy costosa, considerando la multitud de sus ornatos, y lo menudo de ellos, pues no hay parte chica ni grande que no los tenga a montones, de suerte que para distinguirlos a corta distancia, casi se necesita de microscopio. Haga Ud.cuenta que es un hormiguero de cosas en que se disipa la vista. Toda su decoración consiste en ornatos de talla y arquitectura muy desarreglada, y en un gran número de baxos relieves que representan asuntos sagrados».

Ponz se resiste a aprobar los juicios emitidos por el canónigo Juan Gómez Bravo, diciendo que no es la mayor puesto que «las hay sin comparación mejores en España, como son algunas de las referidas en este viaje y que se refieran, la del Escorial, la de los Padres Jerónimos de Guisando, la del monasterio de Huerta, la de Málaga, la de Lugo, y otras diferentes».

Por otro lado, Ceán Bermúdez, enemigo de todo decorativismo y partidario de un clasicismo depurado, alude al trabajo de Cornejo en la Sillería «con suma prolixidad de adornos y medallas» y aclara que «lo de célebre en la arquitectura alude a los malísimos retablos que hizo» ${ }^{5}$. En 1866 Don Luis María Ramírez y de las Casas-Deza ${ }^{6}$ nos habla de la Sillería cordobesa como obra «verdaderamente prodigiosa, que puede contemplarse como una maravilla del arte, aunque sus adornos son profusos y no siempre del mejor gusto, defecto que debe atribuirse a la época en que se trabajó, pero la multitud de figuras que contiene están perfectamente ejecutadas».

Como vamos observando, la mayor parte de los estudiosos que de ella han hablado, hacen hincapié en su gran recargamiento y decoración, aunque reconocen la gran labor ejecutora de Pedro Duque Cornejo. Cuando en 1904 Quintero Atauri publica su trabajo pionero Sillas de $\mathrm{Coro}^{7}$ califica a la sillería cordobesa como «precioso ejemplar del estilo churrigueresco, con todos sus defectos y todas sus bellezas, presentando un aspecto de riqueza y fastuosidad que agrada al primer golpe de vista, pero fatiga tan pronto como se observa en detalle».

Ortí Belmonte, que en 1919 da a conocer los primeros datos documentales de la sillería, critica los medallones de las sillas bajas por repetitivos ${ }^{8}$ y la presenta como una obra decadente. Sin embargo compara su «derroche de inspiración» con la obra «sensible y de tanto mérito» de Verdiguier, tallista francés. Las obras de este último, a juicio de Belmonte, palidecen ante muchas de las esculturas de Cornejo y concluye diciendo que la Sillería de Córdoba es una de las obras más perfectas que ha tallado el barroquismo, aunque produzca a primera vista una sensación de monotonía.

En ese mismo año de 1919 aparece el artículo citado firmado por S.C. (Sánchez Cantón) en el Boletín de la Sociedad Española de Excursiones ${ }^{9}$, donde, tras analizar los juicios críticos de los autores que le precedieron, concluye diciendo que «es obra insigne y que la ola decorativa no destruye sus bellas líneas arquitectónicas y que en los relieves (Cornejo) era frío, pobre de invención y mezquino de técnica: lo que daba el tiempo».

La realización de la Sillería cordobesa partió del legado del señor Arcediano de Córdoba, don José de Recalde, quien en 1742 dejaba «a la fábrica de la Santa Iglesia Catedral de Córdo-

${ }^{4}$ Ponz, A. Viaje de España, Madrid, 1792, T.XVII, pp. 5-7.

5 Cean Bermúdez, J. A. Diccionario histórico de los más ilustres profesores de las Bellas Artes en España, Madrid, 1800, T. II, pp. 21-26.

${ }^{6}$ Ramírez y de las Casas-Deza, L. M.; Descripción de la Iglesia Catedral de Córdoba, Córdoba, 1866, p. 66.

${ }^{7}$ Quintero Atauri, P. Sillas de Coro. Noticia de las más importantes que se conservan en España, Madrid, 1908, pp. 159-160.

${ }^{8}$ Orti Belmonte, M. A. «La Sillería del Coro de la Catedral de Córdoba» en Revista Española de Arte, T.IV, 1919, pp. 237-258.

${ }^{9}$ S.C. «La Sillería de Coro...» art. cit. 1919. 
ba 120.000 reales de vellón, por una vez, para ayuda a la sillería del coro y su facistol...» indicando que dicho dinero debía gastarse en el plazo de cuatro años « y que no empleándose dentro del término expresado se conviertan y gasten en otros usos y necesidades de la misma fábrica» ${ }^{10}$. Tras las peripecias ocurridas para conseguir la madera de caoba, se plantea el no fácil asunto de decidir el artista que labrará la obra. Para ello presentaron modelos Tomás Pedrajas y Alonso Gómez e incluso «el maestro de Salamanca que tiene hechas varias sillerías, que corre con el mayor crédito...». En 1745, fecha en la que se presentan estos diseños, Manuel de Larra y Churriguera había concluido su intervención en la Sillería de Guadalupe ${ }^{11}$; además, había intervenido también en la de Salamanca, por lo que podría perfectamente haber sido él «el maestro de Salamanca» que presentó diseños; incluso, en uno de los pagos se alude a un Churriguera: «más pagué por los dibujos, modelos y monteos de Churriguera, Pedrajas y Gómez, pretendientes de la obra de la sillería... 3614 Rs.».

También presentará sus servicios Francisco Galiano, maestro escultor de la ciudad de Cádiz. Finalmente el 4 de abril de 1747 llega a Córdoba Pedro Duque Cornejo con su hijo, presentando diseños y el modelo de una silla de pino que hizo en Sevilla y se decidió que fuera Pedro Duque Cornejo el maestro que realizara la obra. El 31 de octubre de 1747 se firma una escritura entre los Diputados de la Sillería y Don Pedro Duque Cornejo, por la que se le encarga la dirección y ejecución de la Sillería. La escritura consta de diez cláusulas y entre las más interesantes cabe resaltar lo siguiente: que se obligaba a Pedro Duque Cornejo a permanecer en Córdoba y a ejecutar la obra sin mudar ni quitar nada sin consentimiento de los diputados, además de indicarle los motivos que habrían de incluirse en los medallones de las sillas altas: Los misterios de Nuestro Redentor, y en la otra los de Nuestra Señora y se precisa que serían «según que se eligiere por dichos señores, haciendo antes de la ejecución un modelo para que dichos señores lo vean y puedan quitar o poner lo que les pareciere».

Por todo lo expuesto queda bastante claro que la dirección del programa iconográfico habría de quedar a entera satisfacción de los diputados de Sillería, los comitentes de la obra, y el artista se limitaría a seguir sus indicaciones. En este sentido sería D. José de Capilla Bravo, canónigo Lectoral de Sagrada Escritura de la Catedral, pieza importante en el programa, junto con los otros diputados don Juan Goyeneche, don Francisco José Savariego Recio y don José Fernández Zapata y Carvajal. Esto resulta evidente en la realización de los medallones pequeños de la Sillería alta; éstos son, precisamente, los que vamos a estudiar con más detenimiento en relación a las fuentes grabadas que fueron utilizadas para su realización por Duque Cornejo.

En la Clausula cuarta del contrato que hace referencia a los medallones pequeños de la sillería alta se establece lo siguiente:

"Que asimismo se obliga al dicho Pedro a poner en cada una de las sillas altas otra medalla historiada, arreglada, en la que se ha de poner el caso de la Sagrada Escritura que se le señalare y por cada una de éstas se le han de pagar ocho pesos de a 15 reales cada uno».

En este párrafo, tomado del libro de cuentas de la Sillería, queda claro que los asuntos le serían suministrados por parte de los diputados. Es posible que se le facilitasen también los mode-

${ }^{10}$ El estudio documental de la ejecución de la Sillería de Coro fue abordado primeramente por; Orti Belmonte, M. A. «La Sillería del Coro...» art. cit., 1919. Posteriormente y más in extenso en; Agular Prieto, R. «Bosquejo histórico de la ejecución de la Sillería del Coro de la Catedral de Córdoba» en Boletín de la Real Academia de Ciencias, Bellas Letras y Nobles Artes de Córdoba, año XVII, 1946, n. 55, pp. 173-214. Posteriormente Martín Ribes, J. Sillería del Coro de la Catedral de Córdoba, Córdoba, 1981.

Los datos documentales que han sido utilizados por los anteriores investigadores se encuentran en el libro de cuentas de la Sillería que se halla en el archivo de la Catedral de Córdoba.

${ }^{11}$ Andrés Ordax, S. «El escultor Alejandro Carnicero: Su obra en Extremadura» en Norba Arte, 1980, pp. 10-25. 
los, a través de la Biblia ilustrada, limitándose éste a inspirarse en ella. Aroca Lara ${ }^{12}$ señaló ya en su estudio sobre la Sillería cordobesa la intervención de un mentor - Obispo y diputados- en los asuntos iconográficos, apuntando la utilización, como fuente, de una Biblia de Venecia de 1627. Hernández Díaz, por su parte, señalaba gran número de fuentes literarias y gráficas aunque no se precisaba el modo en como el artista las utilizó ${ }^{13}$. Otro aspecto importante fue el apuntado por Taylor quien, además de precisar algunos motivos profanos, destacó las relaciones entre la obra de Cornejo y la Iconología de Cesare Ripa ${ }^{14}$. Posteriormente, Moreno Cuadro ${ }^{15}$ identificó certeramente relaciones entre los asuntos del Génesis y los de una Biblia Sacra editada en Venecia en 1677 por N. Pezzana. Los temas identificados son: La visión de la escala en Betel, La Bendición de Jacob, el Holocausto de Noé, el Sacrificio de Isaac y la Adoración del Becerro de oro.

En nuestro estudio daremos a conocer más relaciones entre los medallones y la Biblia Sacra de Nicolaus Pezzana, Venecia, 1732, cuya edición más antigua localizada es de 1606, pero cuyos grabados debieron ser realizados a fines del Xvi. Esta Biblia, además de presentar los grabados citados por Moreno Cuadro, proporciona otros muchos modelos que utilizaremos en nuestro trabajo ${ }^{16}$.

Los asuntos que hemos identificado en los medallones del lado derecho son: Aparición del Angel al profeta Balaam, La muerte de Sísara en la tienda de Jael, Sansón desquijarando a un león, muerte de Goliat por David, José atraviesa con su lanza a Absalón.

Medallones del lado izquierdo: La consulta de Herodes a los Doctores sobre el Nacimiento del Mesías, La Reina de Saba visita a Salomón, Esther y Asuero, David bailando delante del Arca, David presenta a Saúl la cabeza de Goliat, Esther a los pies de Asuero y Judith corta la cabeza a Holofernes.

El hecho de utilizar los grabados que ilustran las escenas del Antiguo Testamento como fuente para realizar la obra no debe extrañar, ya que era proceso habitual en otras sillerías barrocas españolas, casos como la de la Catedral y el convento de San Sebastián, ambas en Orihuela ${ }^{17}$. Además, Pedro Duque Cornejo, al igual que otros artistas de su tiempo, dispuso de un buen número de estampas, dibujos y modelos para ejecutar sus obras, como bien queda de manifiesto en el testamento del escultor ${ }^{18}$. Las escenas que se le señalaron al escultor para los medallones pequeños de la Sillería alta, son las del Antiguo Testamento, pero sin un orden claro lo que dificulta su lectura iconológica, observándose la colocación arbitraria a capricho de los diputados de la Sillería.

12 Aroca Lara, A. «Notas para un estudio iconográfico e iconológico de la Sillería del Coro de la Catedral de Córdoba» en Boletín de la Real Academia de Córdoba de Ciencias, Bellas Letras y Nobles Artes, Córdoba, 1979, n. 100, pp. 369385. Ver nota 12 .

${ }^{13}$ Hernández Díaz, J. «El sevillano Pedro Duque Cornejo en el barroco andaluz 1678-1757» en Boletín de Bellas Artes 2. ${ }^{a}$ época,n.VII, Sevilla, 1979, pp. 228-229. Del mismo autor, Pedro Duque Cornejo, «Arte Hispalense», nº 34, Sevilla, 1983.

${ }_{14}$ Taylor, R. ; El entallador e imaginero Pedro Duque Cornejo (1688-1757), Instituto de España, Madrid, 1982, pp. 55-66.

${ }_{15}$ Moreno Cuadro, F. «Algunas fuentes grabadas para la Sillería de la Catedral de Córdoba» en Apotheca, n. 4, 1984, pp. 167-176. Del mismo autor, «Relieves secundarios de la sillería del Coro de la Catedral cordobesa» en Cajasur, n. ${ }^{\circ} 22$, 1986.

${ }^{16}$ Una edición posterior de la presente Biblia puede ser consultada en la Biblioteca del Centro de Estudios Históricos del C.S.I.C.; sig. HA 1678/1 G; Biblia Sacra vulgatae editionis Sixti V \& Clemen. VIII Pont Max Auctoritate recognita. Notis chronologicis, historicis, et geographicis illustrata juxta editionem Parisiensis Antonii Vitre. Nunc demo revisa, et optimis exemplaribus adaptata. Cum indicibus copiosissimis, Venetiis, apud Nicolaum Pezzana, 1754.

17 Sebastián, S. y Martín Caselles, A. El Coro de la Catedral de Orihuela, Valencia, 1986. Sáez Vidal, J. La Sillería del convento de San Sebastián de Orihuela: Estilo e Iconografía, Alicante, 1993.

${ }_{18}$ Valverde Madrid, J. «Testamento del escultor Pedro Duque Cornejo», Diario Informaciones, Córdoba, 30-12-1966. «...Asimismo, fue voluntad de dicho Pedro, mi difunto marido, que se le diesen a don José su hijo y mio, todos los modelos, dibujos y trazas que tenía ejecutados para el ministerio que ejercia y que se aprovechase de ellos...» 
Los medallones pequeños recorren toda la sillería alta de derecha a izquierda, situándose treinta a cada lado. La ordenación, que comienza de manera cronológica con el pecado original, sufre un completo trastueque, que impide toda clase de conclusiones acerca de la ordenación del programa. Aroca Lara, que lo estudió de manera detenida, planteó la hipótesis de que pudiera existir relación entre las escenas del Nuevo Testamento de los relieves grandes y los pequeños que nosotros estudiamos; pero su búsqueda fue infructuosa, deduciendo que la premura por el término de la obra hizo que no se fijara un programa con un claro sentido iconológico.

La primera escena que analizaremos en relación a la Biblia Sacra es la de La Burra de Balaam, (Fig. 1-2) que cuenta la aparición del ángel del Señor a Balaam, el cual iba montado en su burra, y al ver ésta al ángel en el camino con la espada desenvainada, se desvió a un lado. Balaam, enfurecido, pegó a la burra al desviarse de la senda; pero el ángel reprochó a Balaam su furia y en ese momento Balaam vió al ángel del Señor parado en el camino con la espada desnuda, y postrándose en tierra, lo adoró. (Números, Cap. XXII). La escena que, como vemos, se inspira muy directamente en la estampa de la citada Biblia, se desarrolla en medio de una senda con setos y arbustos que se han tomado del modelo apuntado, al igual que la contraposición de actitudes en el ángel, la burra y Balaam.

El siguiente asunto narra La muerte de Sísara en la tienda de Jael(Fig. 3-4). Cuenta cómo Jael tomó un clavo de la tienda y un martillo y trepanó el cerebro de Sísara hasta la tierra, dándole muerte (Jueces, Cap. IV). En esta ocasión el modelo grabado ha sido utilizado con mucha más libertad, sirviéndose tan sólo de la disposición de Jael y de sus aditamentos, aunque se ha invertido la figura de la estampa como veremos en otros ejemplos.

El caso de Sansón desquijarando al león (Fig. 5-6) es también ejemplo de inspiración sin una completa fidelidad, sino sólo tomando algunas actitudes y posturas, sobre todo del león, que está tomado del que aparece en el lateral de la estampa. Narra este episodio el ataque del león a Sansón cuando éste iba a hablar con su futura esposa y la victoria del mismo, cuando despedaza al león sin arma alguna (Jueces, Cap. XIV).

El relieve de La muerte de Goliat por David es uno de los ejemplos más claros de que no se respetó un programa iconográfico con un sentido, ya que el relieve que debía seguir a esta historia, David presentando a Saúl la cabeza de Goliat, se sitúa en la gualdera de la izquierda. Ambas escenas han sido realizadas tomando como modelo la misma estampa. Para La muerte de Goliat, (Fig. 7-8) Duque Cornejo recurre a la parte izquierda de la estampa, adoptando la misma postura de David, dispuesto a cortar la cabeza de Goliat (Libro I de Samuel, Cap. XVII). Con respecto a David presentando a Saul la cabeza de Goliat (Fig. 9), se ha recurrido, por parte del escultor, a la parte derecha de la estampa, inspirándose tanto en la tienda de campaña como en el estrado y en la disposición de Saúl que observa atentamente la cabeza que le muestra David. El grupo de guerreros del fondo también ha servido a nuestro escultor para componer la escena (Libro I de Samuel, Cap. XVII).

Retomando los relieves del lado derecho, la siguiente escena que ha sido configurada teniendo presente la citada Biblia de Venecia, es el relieve de José atravesando con su lanza a Absalón (Fig. 10-11). Se narra en esta escena la muerte de Absalón y la derrota de Israel por tropas de David. Huyendo Absalón montado en un mulo se metió en una encina, enrredándosele la cabellera y quedando colgado en el aire entre cielo y tierra. Aprovechando esta circunstancia, Joab cogió tres dardos, sustituidos en el relieve y el grabado por una lanza, y los clavó en el corazón de Absalón, rematándolo posteriormente los escuderos de Joab (Libro II de Samuel, Cap. XVIII).

En esta ocasión el seguimiento de la estampa es absoluto, tanto en la encina como en la figura de Absalón y la de los jinetes que lo hieren con la lanza, evidenciándose en ambas composiciones la capacidad de adaptarse al espacio que encierra la escena, descrita con una gran capacidad narrativa. 
En los asuntos correspondientes al lado izquierdo, la primera composición que ha sido seleccionada de la Biblia que estamos analizando es La consulta de Herodes a los Doctores sobre el Nacimiento del Mesías (Fig. 12-13). Se narra el momento en que Herodes convoca a los príncipes de los sacerdotes y a los escribas del pueblo y les pregunta dónde había de nacer Cristo. A lo que ellos respondieron: «En Belén de Judá, que así está escrito en el Profeta». (San Mateo, cap. II). El relieve ha sido realizado invirtiendo la composición de la estampa y tomando sólo la escena de la izquierda. Se elige la figura de Herodes, el estrado y al Príncipe que está siendo interrogado, así como los que aparecen en el fondo contemplando la escena.

El siguiente relieve que depende muy directamente de la estampa de la Biblia estudiada, es el de La reina de Saba visitando a Salomón (Fig. 14-15). Cuenta el momento en que la Reina de Saba advierte la sabiduría de Salomón al contestar a sus preguntas y le regala 120 talentos de oro y una gran cantidad de aromas y piedras preciosas. (Libro I de los Reyes, cap. X).

La relación de esta escena con la estampa es bien evidente, observándose la similitud del traje de la reina de Saba en el relieve y la estampa, así como en el estrado y en los leones del lateral y, sobre todo, en el grupo de mujeres que acompañan a la Reina de Saba y las arcadas del fondo.

El relieve de Ester y Asuero(Fig. 16-17) está también realizado tomando como modelo la estampa correspondiente. Se narra aquí el momento en que Ester es coronada como reina en lugar de Vasti y es presentada al pueblo junto con el rey Asuero (Libro de Ester, Cap. I). Los paralelos con la estampa se encuentran tanto en el estrado y escaleras alfombradas como en las actitudes de Ester y Asuero, así como en la decoración a manera de veneras de los respaldos del trono. El relieve de David bailando delante del Arca (Fig. 18-19) es uno de los ejemplos más evidentes de inspiración literal en la estampa de la Biblia analizada. Se cuenta aquí el momento en que David y su gente de la tribu de Judá transportan el Arca de Dios en un carro y danzan delante de ella con todas sus fuerzas, con arpas, salterios, adufes, flautas y címbalos, y el momento en que Oza es castigado por Dios y cae muerto junto al arca (Libro II de Samuel, cap. $\mathrm{VI})$.

Otro ejemplo de desorden en el programa iconográfico aparece en la siguiente escena inspirada en la Biblia. Se trata del relieve de Ester a los pies de Asuero, (Fig. 20-21) que debía acompañar al pasaje anteriormente citado de Ester y Asuero. Se cuenta en esta otra escena la petición de Ester a Asuero de que le salve su vida y la de su pueblo de la maldad de Amán, y la decisión de Asuero de que Amán fuese colgado (Libro de Ester cap. VII). El relieve se realiza de manera invertida a como se representa en la estampa, siendo literal la disposición de Ester, así como el estrado donde se encuentra Asuero. También aparece en la estampa la escena del ahorcamiento de Amán.

El siguiente asunto que presenta analogías con los modelos grabados de la citada Biblia es la del relieve de Judith con la cabeza de Holofernes. (Fig. 22-23) Narra la hazaña de Judith, hija de Mererí, que libró a su pueblo, cortando la cabeza de Holofernes (Libro de Judith, cap. XIII). En este ejemplo, aunque Pedro Duque Cornejo no sigue fielmente la indumentaria de los modelos sí utiliza la estampa como elemento para resolver la composición, así como el cuerpo sin vida de Holofernes que aparece a la derecha postrado.

Finalmente un último relieve que presenta evidentes relaciones con la Biblia de Venecia, es uno de los que aparecen en el testero de la sillería, correspondiente al pasaje del libro primero de los Reyes de las rebeliones de Adab, Razón y Jeroboam (Reyes, 1, cap. XI, 34, 29-31). El asunto cuenta el Encuentro de Jeroboam con Ahías y la partición de la capa (Fig. 24-25) de éste último en diez trozos que regala a Jeroboam como símbolo de las diez tribus que componían el reino de Salomón. En el relieve se observa como se ha seguido la parte derecha de la estampa donde se representa a Jeroboam y Ahías conversando, mientras este último parte la capa. Es pues 
un ejemplo más de inspiración en los pasajes que ilustran la citada Biblia que sin duda alguna hubo de tener muy a la mano el escultor Pedro Duque Cornejo.

Pero aparte de estas fuentes grabadas presentes en la citada Biblia, el impulso creativo de Pedro Duque Cornejo hubo de beneficiarse de otras fuentes, ya que lo que llama poderosamente la atención es el sentido narrativo y descriptivo presente en los relieves, tanto en los pequeños del coro alto, como en los grandes. En éstos de mayor tamaño, como ya se ha señalado por Hernández Díaz ${ }^{19}$, Taylor ${ }^{20}$ y Díaz Vaquero ${ }^{21}$, lo que cautiva es precisamente el pictoricismo presente en las escenas, pues agrupan a veces hasta cuatro figuras aprovechando el espacio de manera prodigiosa y entendiendo el relieve como si se tratara de un auténtico cuadro pictórico, en el que la superposición de los planos está muy estudiada conforme a un cuidadoso análisis de la perspectiva. No es difícil encontrar en estas escenas recuerdos de composiciones de los principales maestros andaluces del barroco, pero sobre todo lo que presentamos ahora es el indudable débito del escultor sevillano con los dibujos del cordobés Antonio del Castillo y Saavedra (1616-1668).

La relación no puede extrañar, toda vez que los dibujos de Castillo eran ya famosos en el siglo XVIII y se guardaban como objetos preciadísimos por coleccionistas y aficionados, tal y como manifiesta Antonio Palomino en el Museo Pictórico y escala óptica, Madrid, 1715-24.

La relación se establece entre la escena del coro alto de San José saliendo de su casa ${ }^{22}$, (Fig. 26-27) después de haber repudiado a la Virgen, y el dibujo de Castillo conservado en el Museo de Bellas Artes de Córdoba de San Pedro ${ }^{23}$. Este modelo ofrece a Cornejo el tipo de figura caminante girada y llevando bajo el brazo el hato, a la que Cornejo sabe dotar de variantes en el tipo de plegado. Es pues probable que el escultor sevillano contase con este dibujo a la hora de ejecutar el modelo del San José, pues como hemos dicho más arriba a su muerte legó a su hijo José, los dibujos y modelos para el ministerio que ejercía.

Nuevamente se pone de manifiesto lo importante que resulta a los artistas tanto las estampas como los dibujos en el proceso de la creación artística, sirviéndoles como modelos a la hora de recrear su propia composición, en la que desde luego estaban muy presentes las directrices de los comitentes y en el caso de Cornejo del Cabildo y diputados, que serían quienes controlarían la obra hasta configurar - como ha señalado Taylor - una verdadera Biblia Pauperum a lo moderno ${ }^{24}$.

\footnotetext{
19 Hernández Díaz, art. cit., 1979, pp. 228-229.

20 Taylor, op. cit., 1982, pp. 63-64.

${ }^{21}$ Díaz vaquero, M. . D. La Virgen en la escultura cordobesa del barroco, Córdoba, 1987, p. 161.

22 Véase el análisis iconográfico de Moreno Cuadro, F., Iconografía de la Sagrada Familia, Córdoba, 1994 , p. 77.

${ }^{23}$ Fotografía Archivo Mas n. ${ }^{\circ}$ C-86.546. Dfr. Müller, P. E., The drawings of Antonio del Castillo y Saavedra, New York University, Ph.D., 1963, p. 314, fig. 60.

${ }^{24}$ Taylor, op. cit, 1982, p. 63.
} 

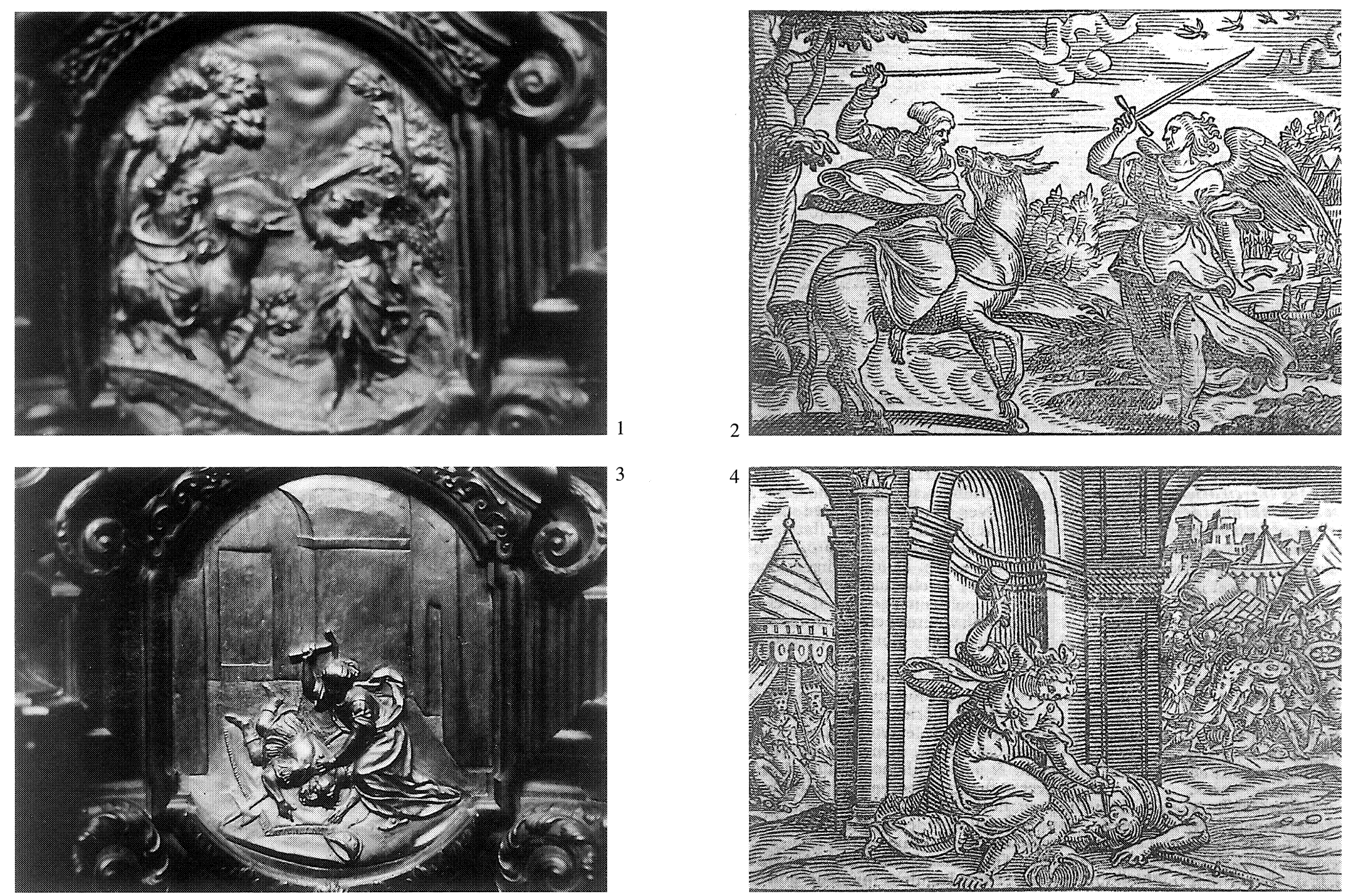

Fig. 1. Pedro Duque Cornejo. La Burra de Balaam. Córdoba. Sillería de la Catedral. Fig. 2. La Burra de Balaam. Grabado de la Biblia de Pezzana.

Fig. 3. Pedro Duque Cornejo. La muerte de Sísara en la tienda de Jael. Córdoba. Sillería de la Catedral. Fig. 4. La muerte de Sisara en la tienda de Jael. Grabado de la Biblia de Pezzana. 

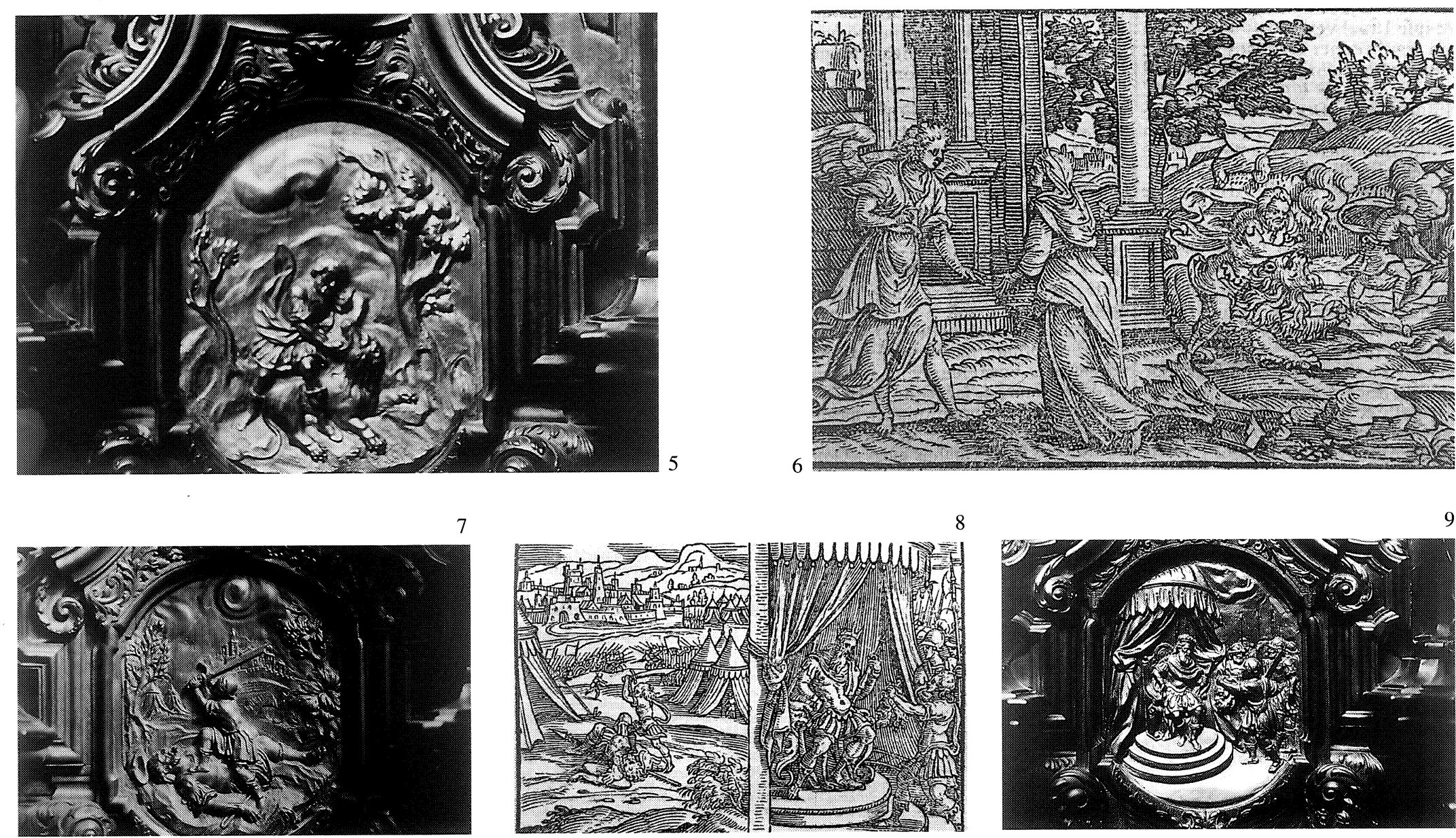

7
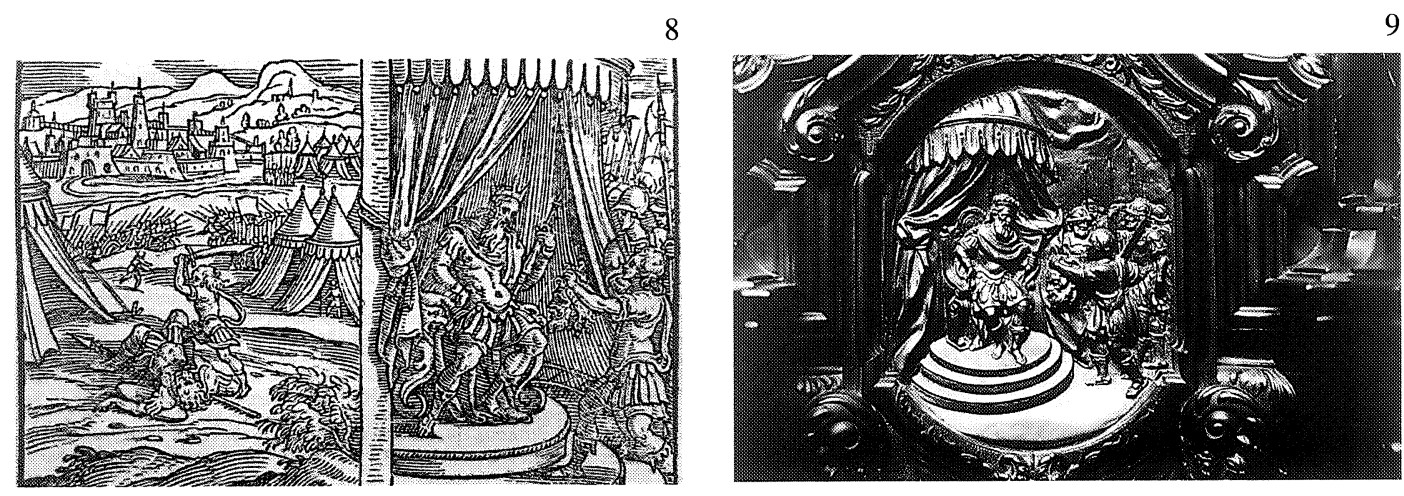

Fig. 5. Pedro Duque Cornejo. Sansón desquijarando el león. Córdoba. Sillería de la Catedral.

Fig. 6. Sansón desquijarando el león. Grabado de la Biblia de Pezzana.

Fig. 7. Pedro Duque Cornejo. La muerte de Goliat por David. Córdoba. Sillería de la Catedral.

Fig. 8. Muerte de Goliat y David presentando la cabeza a Saúl. Grabado de la Biblia de Pezzana.

Fig. 9. Pedro Duque Cornejo. David presentando la cabeza de Goliat a Saúl. Córdoba. Sillería de la Catedral. 

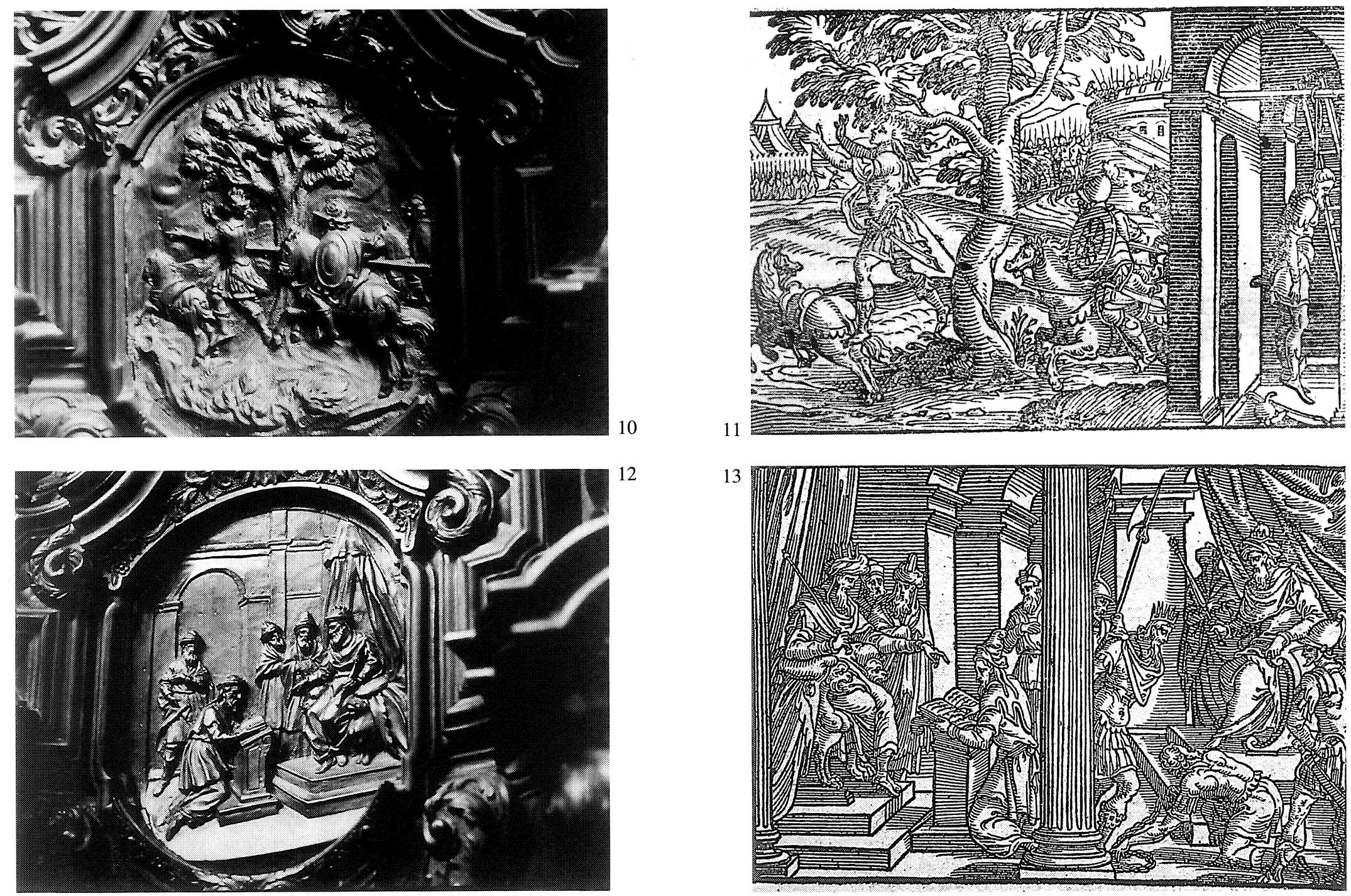

Fig. 10. Pedro Duque Cornejo. Joab atravesando con su lanza a Absalón. Cordoba. Sill

Fig. 12. Pedro Duque Cornejo. La consulta de Herodes a los doctores sobre el nacimiento del Mesías. Córdoba. Sillería de la Catedral.

Fig. 13. La consulta de Herodes a los Doctores sobre el nacimiento del Mesías. Grabado de la Biblia de Pezzana. 

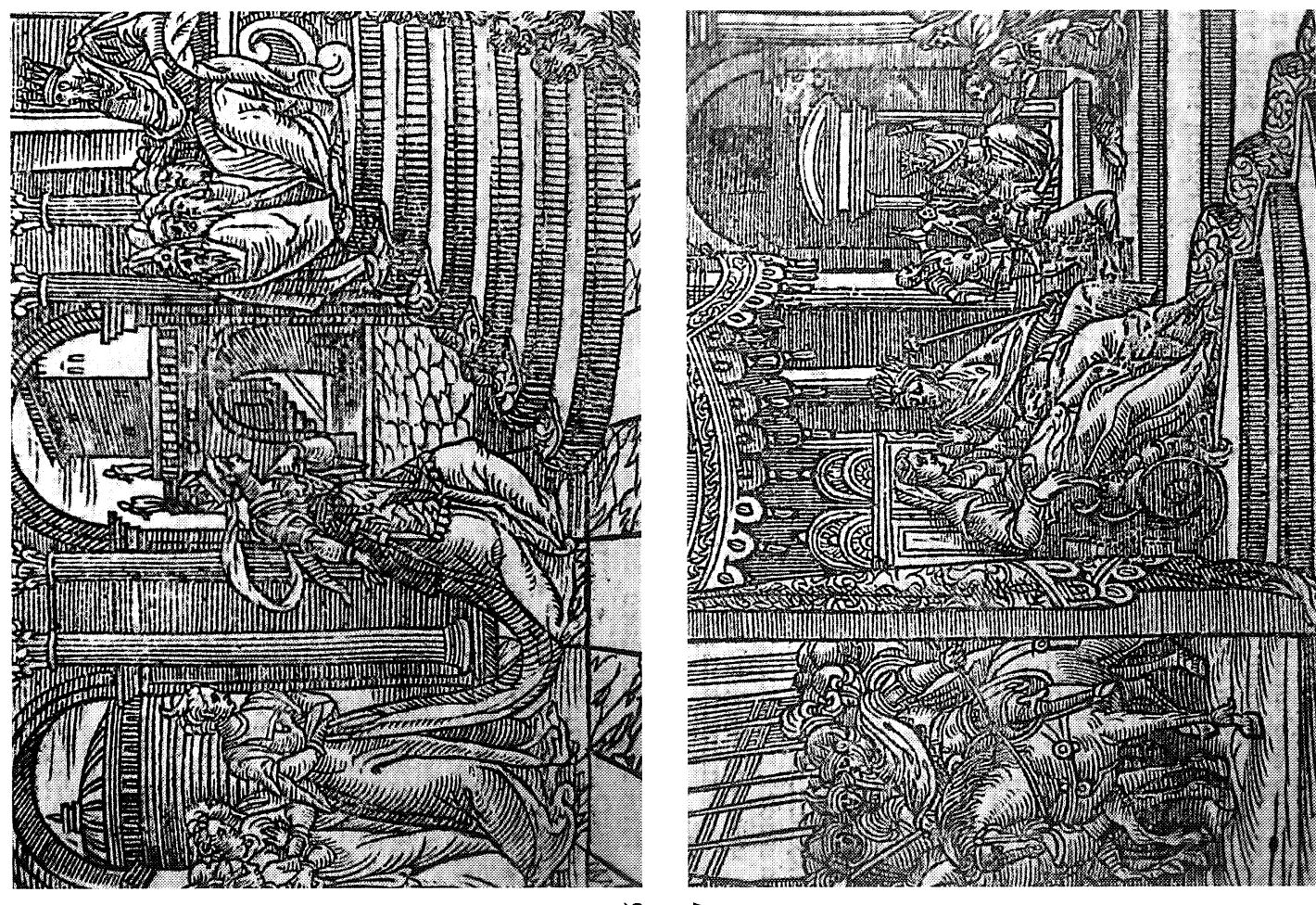

焉

$\pm \quad 0$
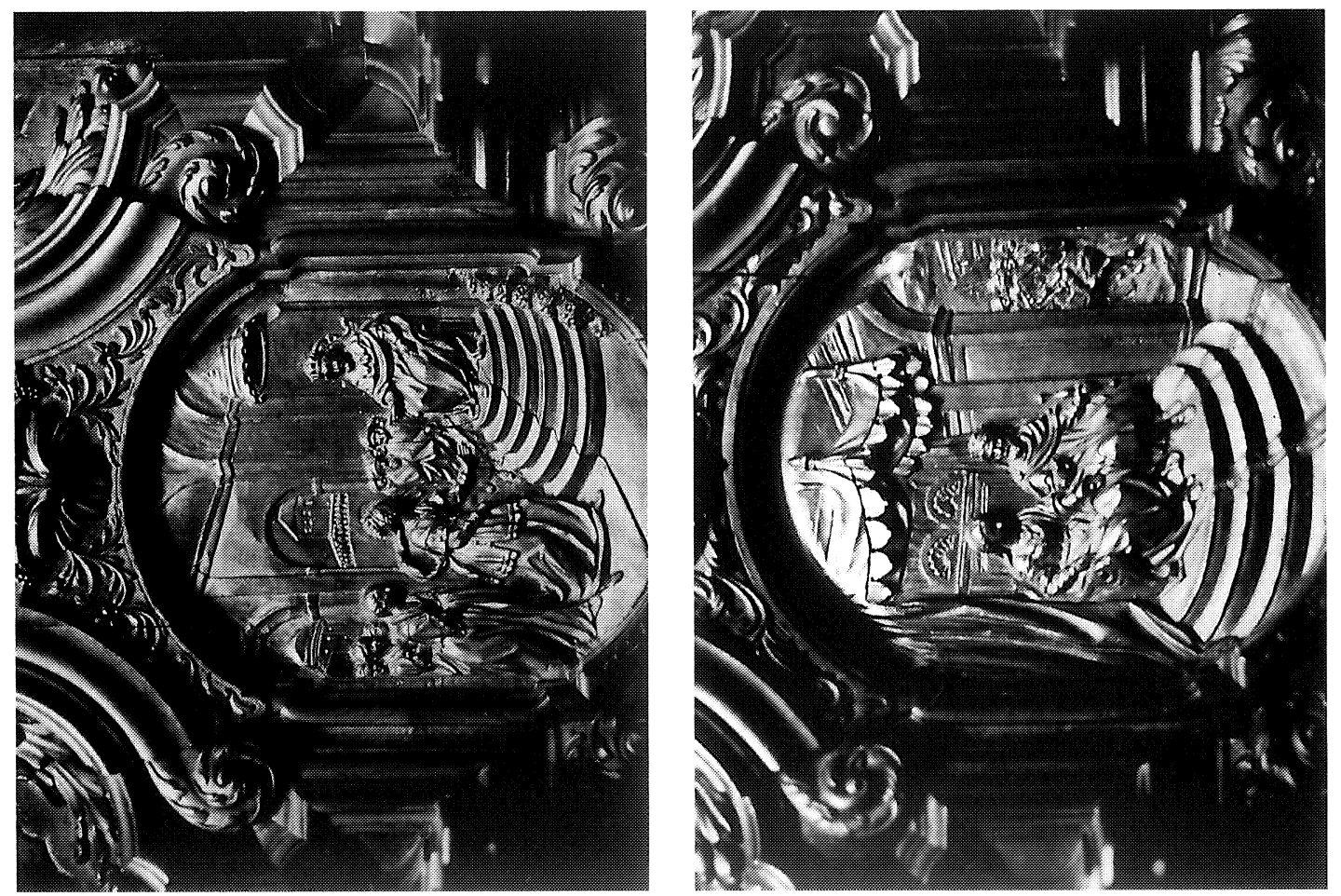

ชิ่ 똟

总造

$\therefore$

옹 웜

它

常

유ㄹㅠㅠ 율

芆造

8 (1)

के

\& 혼

हี

28

ริ ฐ

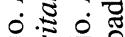

可

ن \& 0

ษ

휴휴

०.ำ

ป

$\dot{t} \dot{0} \dot{1}$

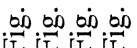



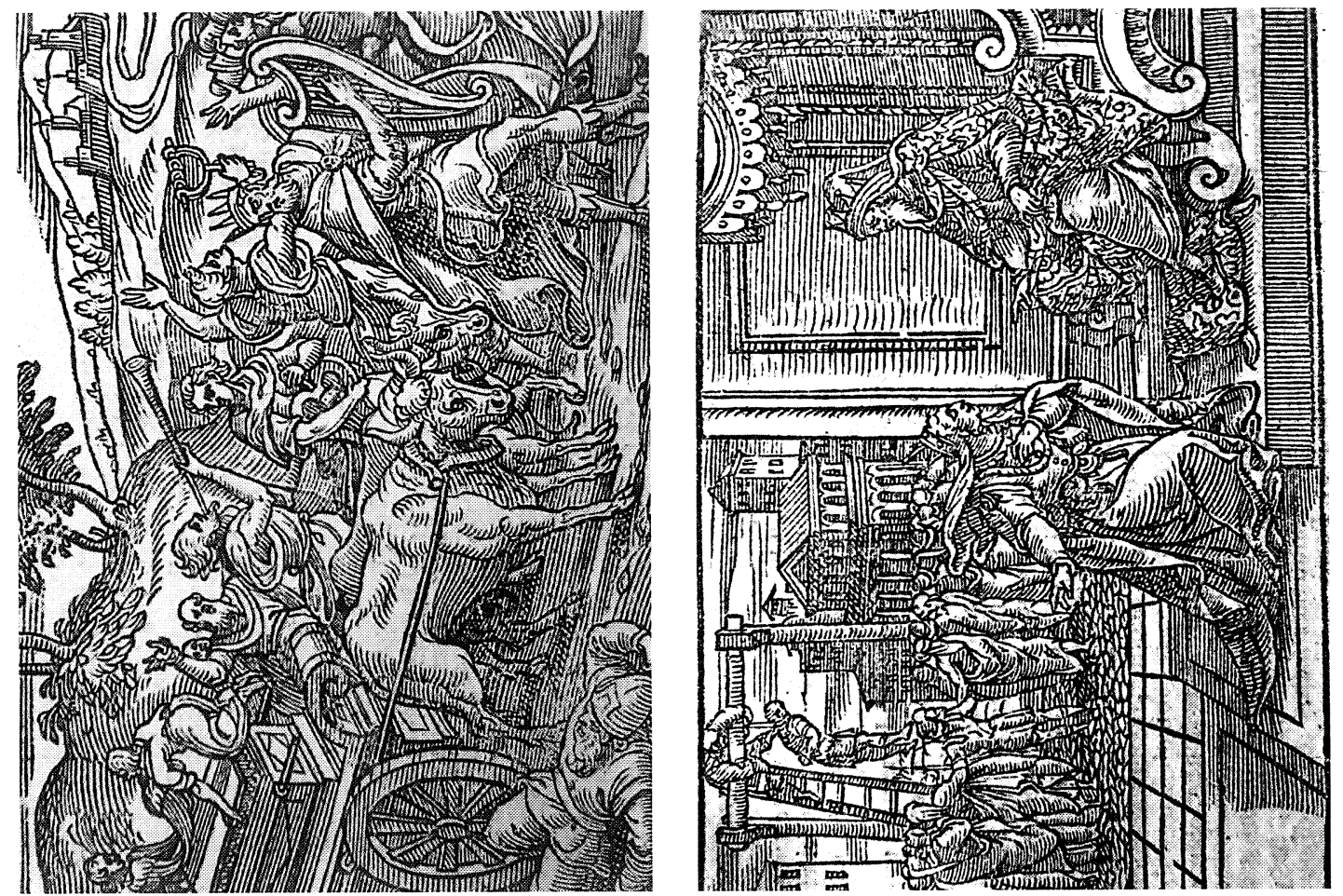

$\curvearrowright \bar{\sim}$

$\stackrel{\infty}{-}$
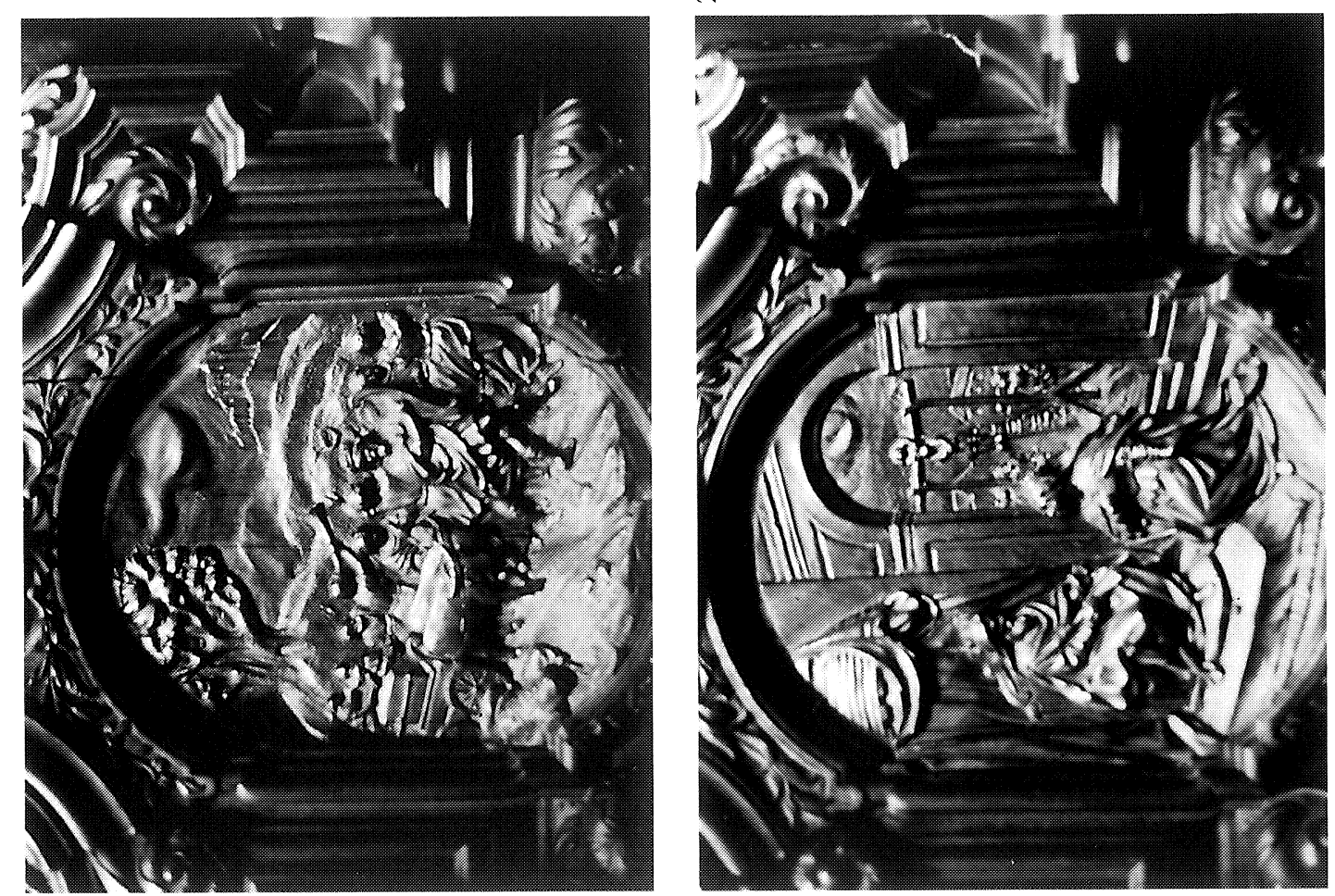

要

น ช่

온

ชิ๊ ถึ่

ช.

윰워

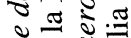

䒓 曹

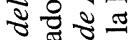

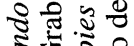

इ 0 죵

ปี

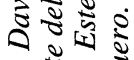

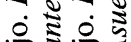

हี

บ 80.

혼

홍 ज्ञ

을 옿웧

20.

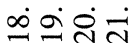

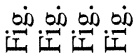



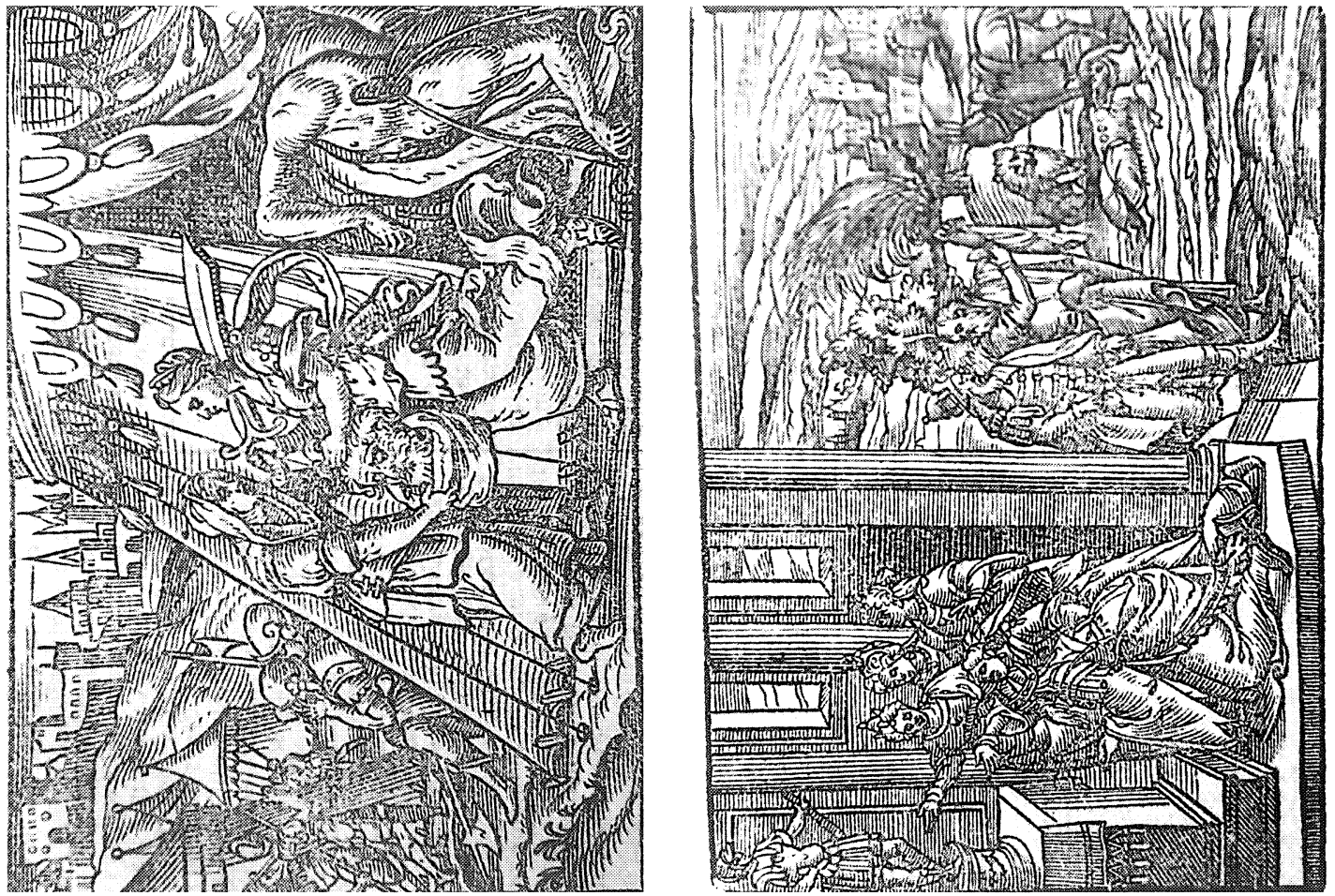
光

ป
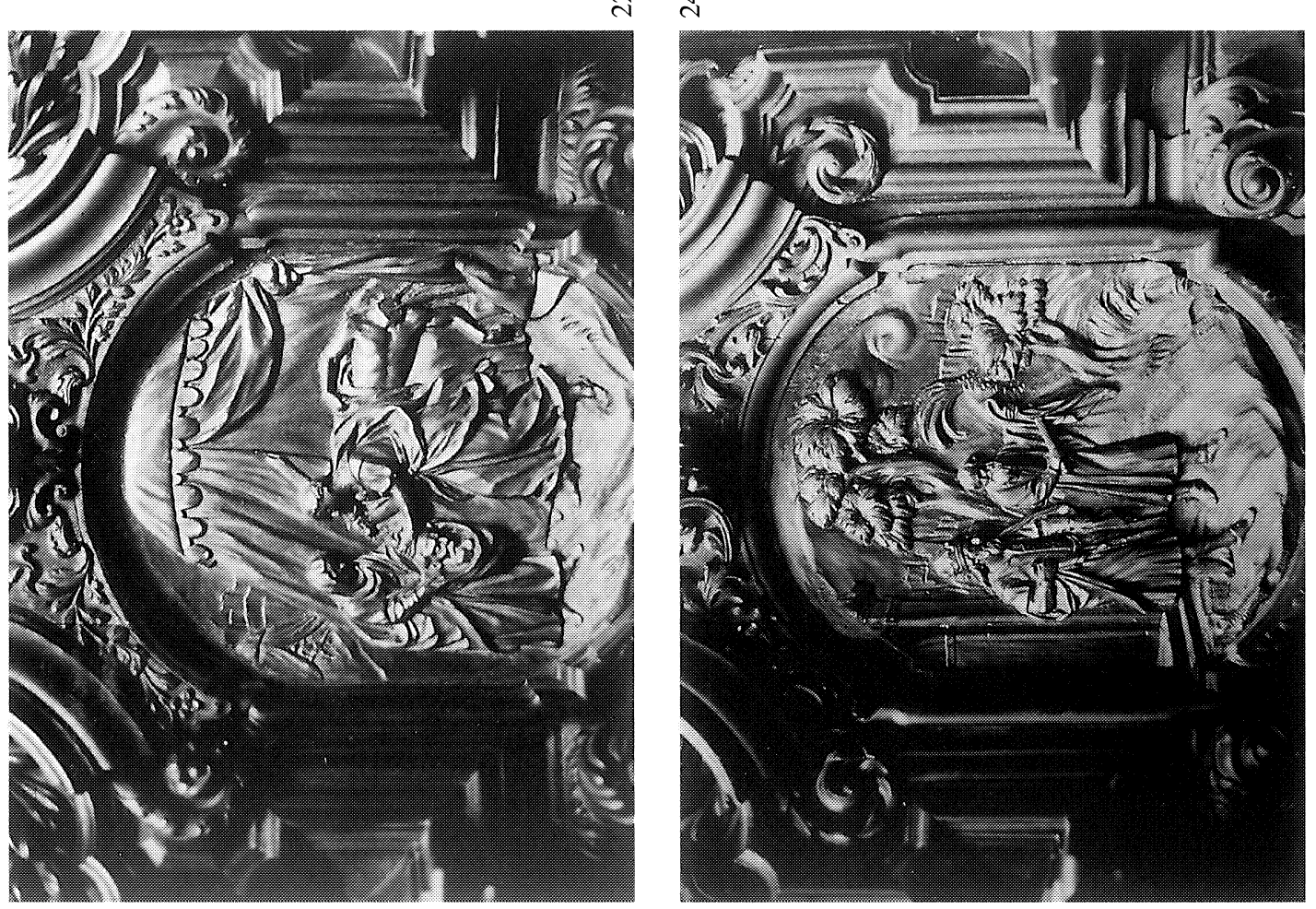

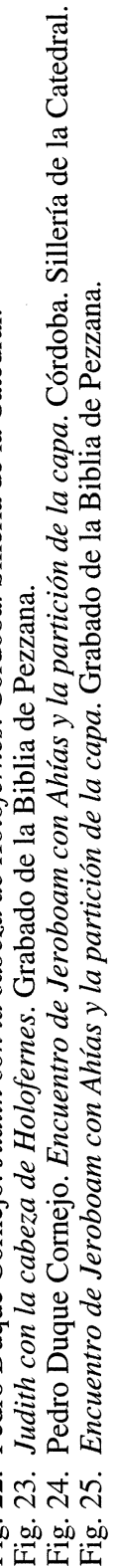




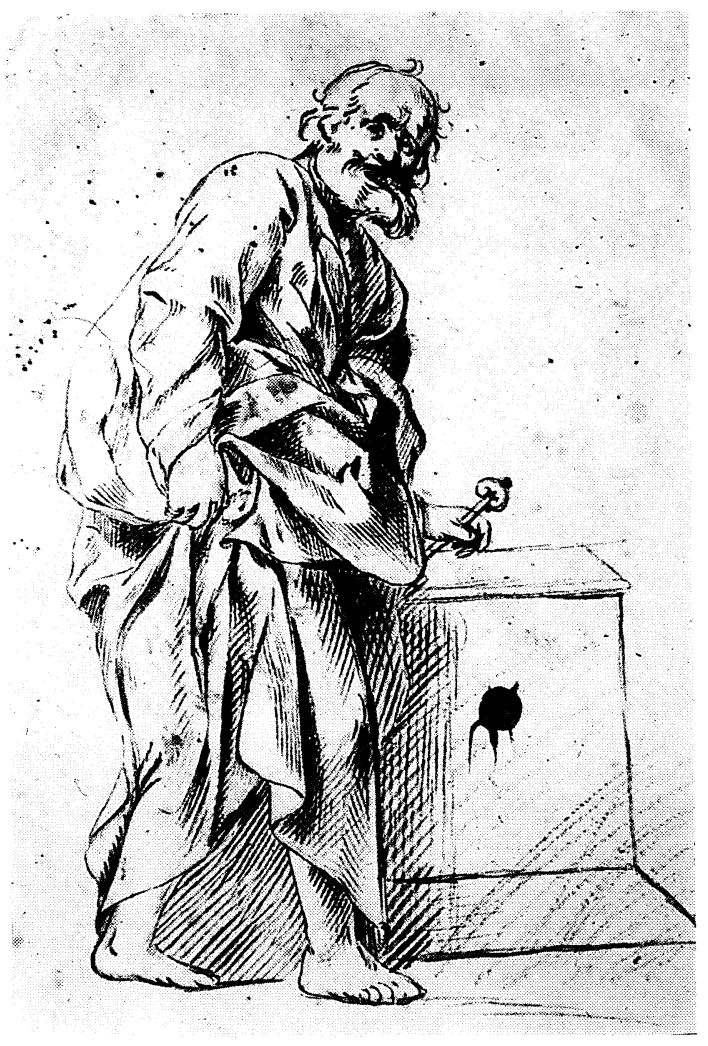

26

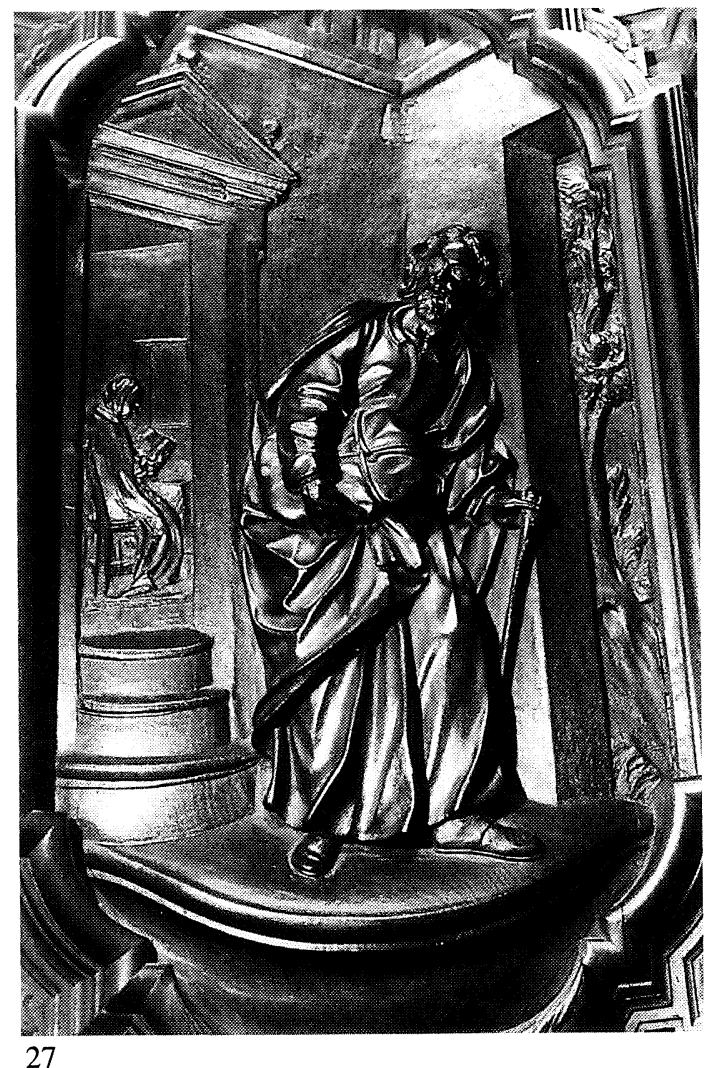

27

Fig. 26. Pedro Duque Cornejo. San José saliendo de su casa. Córdoba. Sillería de la Catedral (relieve grande del coro alto).

Fig. 27. Antonio del Castillo y Saavedra, San Pedro, Córdoba. Museo de Bellas Artes. 